\title{
Nocturnal enuresis: A topic review and institution experience
}

\author{
John Michael DiBianco, Chad Morley, , Osama Al-Omar ${ }^{1}$
}

Ross University School of Medicine, Roseau, Commonwealth of Dominica, West Indies, ${ }^{1}$ Department of Surgery, Division of Urology, West Virginia University Robert C. Byrd Sciences Center, Morgantown, WV, USA

\begin{tabular}{|c|}
\hline Access this article online \\
\hline Website: www.avicennajmed.com \\
\hline DOI: 10.4103/2231-0770.140641 \\
\hline Quick Response Code: \\
\hline
\end{tabular}

\begin{abstract}
The objective is to provide a review of nocturnal enuresis (NE), including its epidemiology, etiology, pathophysiology, evaluation, and current management. We also set to provide further insight on the treatment of this condition from the experience derived from patients cared for at our tertiary-care institution. NE affects approximately $15 \%$ of all children at 5 -year-old, affecting boys more frequently than girls. At our large university tertiary pediatric urology center, $\mathrm{NE}$ and incontinence, in general, is one the most common chief complaints prompting urologic care. In this review, we examine the condition in detail, highlighting specific goals of the initial evaluation and treatment. We contrast the commonly implemented treatment recommendations, available from the literature with strategies we have found valuable from our extensive experience in treating patients with this disorder. Using current urologic reference textbooks, book chapters, Medline, journal articles and reviews describing the many aspects of NE were reviewed in order to describe NE and the current practices at our institution. Although, this is not a systematic literature review, it includes relevant available research, institutional experience and urological expert opinion and current practices at a tertiary state health facility. The treatment of NE remains a challenge for many pediatricians and pediatric urologists. This likely stems from the multiple possible etiologies of the disorder. We have established a treatment algorithm at our institution, which we have found successful in the majority of our patients. This consists of starting patients on urotherapy, then offering both the enuresis alarm device and medication therapy as first line treatments, and finally adding anticholingerics for combination therapy. Our hope is with further research the treatment of NE will continue to improve.
\end{abstract}

Key words: Bedwetting, desmopressin, dysfunctional voiding, nocturnal enuresis, nocturnal polyuria

\section{INTRODUCTION}

When faced with a distraught child and frustrated parents, the challenge of treating a child with nocturnal enuresis (NE), can be overwhelming to many physicians. At our large university tertiary-care, pediatric urology center, NE, and incontinence in general, is one of the most common chief complaints prompting urologic care. In this manuscript, we review the available information on the epidemiology, etiology, pathophysiology, evaluation and current management of NE. We contrast the commonly implemented treatment recommendations, with strategies we have found valuable from our extensive experience in treating patients with this disorder.

\section{Defining the disease}

The definition of NE, accepted by most experts today and used in this manuscript, was standardized by Nevéus et al., on behalf of the International Children's Continence Society (ICCS) in 2006 and updated by Austin et al. in 2014, in the context of an article describing the function of the lower urinary tract (LUT) of children and adolescents [Figure 1]. ${ }^{[1,2]}$

Nocturnal enuresis, commonly known as "Bed Wetting", is a disorder in which episodes of urinary incontinence (uncontrollable leakage of urine) occurs during sleep in children $\geq 5$ years of age. ${ }^{[2]} \mathrm{NE}$ can be present with or without LUT symptoms. When only NE is present, the disorder is referred to as monosymptomatic enuresis. In 
Enuresis: Discrete episodes of urinary incontinence during sleep in children $\geq 5$ years of age
Monosymptomatic Enuresis: enuresis in children without any other lower urinary tract symptoms and without a history of bladder dysfunction

Non-Monosymptomatic Enuresis: enuresis in children with other lower urinary tract symptoms
Primary: Children who have never achieved a satisfactory period of nighttime dryness

Secondary: Children who develop enuresis after a dry period of at least six months

Figure 1: Defining enuresis algorithm (adapted from Austin et al. 2014)

the presence of other symptoms, the disorder is referred to as nonmonosymptomatic enuresis. Typically additional symptoms, in the nonmonosymptomatic enuresis patient reflect LUT dysfunction. LUT symptoms are typically: LUT pain, increased voiding frequency ( $\geq 8$ times/day), decreased voiding frequency ( $\leq 3$ times/day), daytime incontinence, urgency (sudden and unexpected feeling of immediate need to void), hesitancy (difficulty initiating voiding), straining (application of abdominal pressure to initiate and maintain voiding), weak or intermittent stream (weak force of urine ejection and/or micturition occurring in several discrete spurts) and spraying urinary stream. ${ }^{[1]}$

Nocturnal enuresis is subdivided into primary and secondary forms. ${ }^{[1]}$ Primary enuresis is the presence of enuresis in a child $\geq 5$ years old who has never achieved an asymptomatic period ( $\geq 6$ months) of consistent nighttime dryness. ${ }^{[3]}$ Secondary enuresis is the presence of enuresis in a child $\geq 5$ years old who has achieved an asymptomatic period ( $\geq 6$ months) of consistent nighttime dryness in the past. ${ }^{[3]}$ Secondary enuresis is most commonly triggered by an unusually stressful life event, significant enough to cause psychosocial regression. ${ }^{[4]}$

Our discussion will elucidate ways in which a physician can delineate the type of NE a child has. We will focus our discussion on the pathophysiology and treatment strategies of children with primary NE, as secondary NE, by definition, has varying underlying mechanisms at which treatment in focused. ${ }^{[4]}$

\section{EPIDEMIOLOGY}

Nocturnal enuresis is approximately twice common in boys than girls. ${ }^{[5-7]}$ It is estimated that approximately $15 \%$ of children have NE at 5 years of age, with most children, $\sim 80 \%$, diagnosed with primary enuresis. ${ }^{[3,8]} \mathrm{NE}$ is typically a self-limited disease, with the percentage of patients affected decreasing with age: $\sim 15 \%$ at 5 yo, $13 \%$ at 6 yo, $10 \%$ at 7 yo, $7 \%$ at 8 yo, $5 \%$ at $10 y o, 2-3 \%$ between $12-14$ yo and $1-2 \%$ incidence at $\geq 15$ yo. ${ }^{[6,9,10]}$ It typically resolves spontaneously at a rate of $15 \%$ /year with persistence at higher ages, diminishing the likelihood that resolution will occur. ${ }^{[6,7,11]}$ About $20 \%$ of these children with NE experience daytime enuresis or LUT symptoms; ${ }^{[12]}$ approximately $15 \%$ of children with NE experience encopresis, the voluntary or involuntary passage of feces in inappropriate places, which shows a strong male predominance. ${ }^{[13]}$

The wide prevalence of NE speaks to the need for an improved understanding of this condition by patients, families, pediatricians, primary care doctors and urologists alike. The association of NE with many other conditions, such as: Cognitive problems, low self-esteem, attention deficit hyperactivity disorder, ${ }^{[14-17]}$ and disturbed sleep, ${ }^{[18]}$ enlarges the need for all clinicians to be able to recognize and evaluate patients with this disorder.

\section{PATHOGENESIS}

The necessity to identify the cause of NE is usually heightened when the clinician is faced with a new, often distressed, patient and his or her concerned parents. The potential multifactorial etiologies, encompassing psychological and physiological aspects of the disorder, frequently compromise the rapid identification of the disorder's pathogenesis. ${ }^{[12]}$ The most common underlying mechanisms of NE include: Nocturnal polyuria, decreased bladder capacity (BC), detrusor overactivity, associated sleep arousal disturbances, decreased $\mathrm{BC}$, global maturation delay, and genetics. NE, most likely, is a disorder caused by a combination of these etiologies in a multifactor manner.

\section{Nocturnal polyuria}

Nocturnal polyuria refers to increased urine production while asleep. The mechanism for nocturnal polyuria can 
include increased fluid intake prior to sleep and/or reduced production or response to antidiuretic hormone (ADH, vasopressin). ${ }^{[19-24]} \mathrm{ADH}$ not only decreases urine production, it has also been shown to aid in the increase of bladder distention. ${ }^{[25]}$ Normally, urine output is decreased during sleep, secondary to circadian changes in $\mathrm{ADH}$ secretion, as seen in children without NE. ${ }^{[26-28]}$ There are two proposed mechanisms regarding $\mathrm{ADH}$, either resistance to $\mathrm{ADH}$, or a reduction in its secretion resulting in an increased urine output. Current studies of resistance to ADH have not been proven, however, nocturnal ADH secretion in children with NE has been found to be less in several studies in comparison to age-matched children without NE. ${ }^{[20-24]}$ Thus, according to this theory, children with NE may not only produce more urine at night (secondary to reduced $\mathrm{ADH}$ ), they may also have a smaller capacity for urine storage (secondary to reduced $\mathrm{ADH}$ effect on bladder distensibility).

\section{Decreased bladder capacity}

A normal bladder at 1 year of age has a capacity of approximately $60 \mathrm{~mL}$ of fluid and increases approximately $30 \mathrm{~mL} /$ year $^{[29]}$ No anatomical differences in bladder size have been observed in children with or without NE. ${ }^{[25,29]}$ However, some studies have demonstrated a reduction in nocturnal bladder function, as opposed to daytime function. Comparing the $\mathrm{BC}$ of children with $\mathrm{NE}$, while awake, and under general anesthesia to healthy, age-matched controls they observed that patients with NE, had significantly decreased voided urine volumes in the absence of any anatomic differences. ${ }^{[30]}$ Other studies have also confirmed that in children with NE, nighttime voided volumes are significantly decreased compared to daytime voided volumes. ${ }^{[26,31]}$ This observation of a reduced functional BC, similar to NE itself, may have a multifactorial cause. ${ }^{[12]}$

\section{Detrusor overactivity}

The detrusor muscle plays an important role in normal voiding patterns; therefore, it has been postulated to play an important role in urinary disorders such as NE. It is theorized, that detrusor overactivity may cause bladder dysfunction in NE due to the finding that children with NE have been shown to have significantly decreased functional bladder capacities compared to healthy age-matched controls, indicating a possible lower pressure threshold for detrusor activity ${ }^{[12,26,32]}$ Children with NE, unlike patients with obstructive bladder dysfunction disorders, when studied urodynamically, do not show dysfunctional voiding patterns or high voiding pressures, indicating possibly isolated detrusor overactivity. ${ }^{[12]}$ Some investigators have postulated that children with primary monosymptomatic NE may have a defect in detrusor inhibition as studies have failed to find evidence for increased uninhibited detrusor hyperactivity. ${ }^{[33]}$

\section{Associated sleep arousal disturbances}

In patients with NE, there is a basic discordance in the ability to arouse from sleep from voiding urge sensation. It is unclear whether this is caused by sleep disturbances or problems with the bladder-brain communication. There are studies that have demonstrated that children with NE have detrusor instability while asleep, but not while awake, ${ }^{[12,32]}$ studies demonstrating that children with NE tend to be "deeper sleepers" than other children, ${ }^{[12,34-37]}$ and other studies finding children with NE to be "light sleepers" ${ }^{[38]}$ or no different than controls. ${ }^{[34,39]}$

\section{Bladder brain connection dysfunction}

One study found patients with NE to have frequent cortical arousals, but an inability to awaken completely. The cortical arousals were associated with unstable bladder contractions, suggesting to the authors that the arousal center may be paradoxically, suppressed by signals from the bladder, leading to bladder brain dysfunction. Several studies demonstrate that during sleep, children with NE have significantly less inhibition of their blink response than healthy controls. ${ }^{[40,41]}$ This inhibition response is controlled by an area of the brain known as the pedunculopontine tegmental nucleus, which is located near the pontine micturition center in the brainstem; when properly treated, sleep arousals and inhibitory responses improved in children with NE. The authors concluded that a reduced ability to inhibit micturition during sleep may originate from a dysfunctional pontine tegmentum. ${ }^{[40,41]}$

\section{Global maturation delay}

Further possible central nervous system (CNS) roles in the etiology of NE have been suggested, hypothesizing neurophysiologic data support differences in the maturation of the CNS of children with NE compared to healthy controls. ${ }^{[32,42,43]}$ These studies have shown that episodes of enuresis are associated with specific findings on electroencephalography (EEG) and in longitudinal studies, as children with NE age, progressive maturation of bladder stability occurs in conjunction with EEG findings that suggest increased CNS recognition of bladder fullness and the ability to suppress the onset of bladder contraction. ${ }^{[32]}$ Thus, it is possible that global CNS maturation delay may be a contributor to NE.

\section{GENETICS}

It has been reported that children of parents who have experienced NE have a higher likelihood of experiencing NE. ${ }^{[4]}$ Supporting a genetic contribution to the etiology of NE, Bakwin et al., reported that monozygotic twins exhibit twice the risk of NE as dizygotic twins in concordance 
studies. ${ }^{[45]}$ These investigators also found a $75 \%$ incidence of NE in children when both parents had a history of NE, compared to $50 \%$ when only one parent had history of $\mathrm{NE}$ and $15 \%$ when neither parent had a history of NE. ${ }^{[4]}$ An unexplained, 25-33\% increased co-incidence of NE in children with sickle cell anemia has been reported compared to age-matched controls. ${ }^{[4]}$ Although no genetic explanation is yet apparent, these studies and findings suggest a genetic contribution to the recognized complex etiology of NE. ${ }^{[4]}$

\section{EVALUATION}

\section{History}

The most important diagnostic step in the evaluation of a patient with urinary complaints is a thorough medical history, involving the elucidation of key information. ${ }^{[47]}$ Table 1 illustrates some of the most important aspects of the history, according to Tu et al., when evaluating a child with NE and correlates positive aspects of the history with their clinical significance. ${ }^{[48]}$ In our experience, it is valuable to especially focus on the timing and duration of symptoms. To differentiate primary versus secondary $\mathrm{NE}$, we inquire whether the child has ever had extended periods of dryness. To differentiate monosymptomatic versus nonmonosymptomatic NE, we recommend asking whether the child experiences symptoms during the day, at night, or both. To discriminate between functional versus anatomical NE, it is valuable to determine if the child has continuous leakage. ${ }^{[12]}$ Along with this line of questioning, we investigate for the presence of associated symptoms (pain, urgency, frequency, holding maneuvers or situational incontinence) ${ }^{\left[{ }^{[9]}\right]}$ We make it a priority to investigate the behavioral aspect of the child's urinary function, including voiding pattern, voiding hygiene, such as incomplete voiding, as well as the child's eating and drinking habits (amount and timing, content), utilizing fluid and voiding diary, in order to differentiate and assess if $\mathrm{NE}$ is representative of or exacerbated by excessive fluid loading. It is important to assess the child's cognitive ability; since, in our experience, functional incontinence may be confused with NE if a child has a cognitive disability. We concur with the experience of others that enuresis and stooling dysfunction are related. ${ }^{[50]}$ To enhance the assessment of stooling habits we recommend the use of an objective tool, like the Bristol stool chart, for added accuracy. ${ }^{[50]}$ It is also crucial to inquire whether the child is motivated to treat their condition which will help in determining first line treatment option (alarm device vs. medication). As we review the wide variety of treatment strategies for NE, it has become clear that whether or not the child is motivated to change, dramatically alters the effectiveness of these strategies. ${ }^{[12]}$

Use of a "bladder diary," the patient's (family's) own record of both voiding events and associated bladder symptoms has been recommended by the ICCS [Table 2]. ${ }^{[1]}$ The diary is designed to include: The timing, frequency and volumes of all voiding events (minimum $48 \mathrm{~h}$ ), number of nocturnal episodes (7 nights), episodes of daytime incontinence (7 days), LUT symptoms (7 days), fluid intake volume/timing/content (minimum $48 \mathrm{~h}$ ), bedtime and sleep interruptions (7 days). The use of a "bowel diary" has also been recommended by the ICCS due to the intimate relationship between bowel and bladder dysfunction and the rate of comorbidity. Like the bladder diary, the child and family are advised to record the number of bowel movements (7 days) and any episodes of encopresis, (7 days). ${ }^{[1]}$ In our experience, we find these tools most valuable, as a supplement, when the history gathered is deemed either

\begin{tabular}{ll}
\hline Table I: Important aspects of the history for a child with nocturnal enuresis \\
\hline Historical feature & Possible significance \\
\hline Daytime symptoms & Dysfunctional voiding \\
Lower urinary tract symptoms (voiding $\geq 8$ or $\leq 3$ times per day, & Dysfunctional voiding or anatomic abnormality (e.g., posterior urethral valves) \\
hesitancy, straining, weak stream, intermittent stream, incomplete & \\
emptying, postmicturation dribble, genital or lower urinary tract pain) & \\
Prolonged period of dryness (>6 months) & Secondary enuresis more often associated with psychologic comorbidities \\
Frequency of episodes & Nightly enuresis is associated with poor prognosis \\
Change in frequency of episodes over time & The natural history is of spontaneous resolution \\
Approximate volume of enuretic void & Estimate of bladder capacity \\
Fluid intake diary & May suggest etiology of nocturnal polyuria (increased afternoon/evening fluid \\
& intake; diabetes mellitus; diabetes insipidus; psychogenic polydipsia) \\
Stooling history & Constipation may contribute to decreased bladder capacity \\
Review of systems & May identify previously undiagnosed medical condition that contributes to enuresis \\
Snoring & Obstructive sleep apnea \\
Weight loss, fatigue & Diabetes, kidney disease \\
Gait abnormalities & Spinal dysraphism \\
Staring spells & Seizure disorder \\
Perianal itching, vulvovaginitis & Pinworms \\
Excessive thirst, nighttime drinking & Diabetes, kidney disease, psychogenic polydipsia \\
Family history of enuresis & Genetic factors may be contributing \\
\hline
\end{tabular}


insufficient or unreliable. We have also experienced difficulty with adherence by both the child as well as their families.

In addition to the previously described history, the ICCS recommends the use of questionnaires in order to quantify the symptomatology of both the LUT symptoms and emotional impact on the patient. ${ }^{[1]}$ In patients where intellectual or behavioral disorders are suspected, the use psychological screening may be beneficial. ${ }^{[1]}$

\section{Physical exam}

The diagnosis of primary monosymptomatic NE will most likely be made from the history alone, however, the physical exam always proves helpful particularly when the etiology of the patient's symptoms is secondary to an underlying medical condition or anatomical abnormality. ${ }^{[19,48,51,52]}$ Table 3 lists the most important aspects of the physical exam when evaluating a child with

\begin{tabular}{|c|c|c|}
\hline \multicolumn{3}{|c|}{ Urodynamic instruments in children } \\
\hline Instrument & Age & Data \\
\hline \multirow[t]{6}{*}{ Bladder diary } & From 5 years & Voided volumes \\
\hline & & Voiding frequency \\
\hline & & Urine output \\
\hline & & Symptom (leakage, etc) \\
\hline & & frequency \\
\hline & & Other data (Appendix 5) \\
\hline \multirow{4}{*}{$\begin{array}{l}\text { Uroflow and } \\
\text { residual }\end{array}$} & From 5 years & Voided volume \\
\hline & & Curve shape \\
\hline & & Urine flow rate \\
\hline & & Residual urine \\
\hline \multirow[t]{5}{*}{ Cystometry } & All ages & Detrusor pressure and activity \\
\hline & & Cystometric bladder capacity \\
\hline & & Compliance \\
\hline & & $\begin{array}{l}\text { Sphincter competence and } \\
\text { activity }\end{array}$ \\
\hline & & Other data (see specific section) \\
\hline \multirow{4}{*}{$\begin{array}{l}\text { 4-Hour voiding } \\
\text { observation }\end{array}$} & Infancy & Voided volumes \\
\hline & & Voiding frequency \\
\hline & & Residual urine \\
\hline & & Observation of symptoms \\
\hline
\end{tabular}

\begin{tabular}{|c|c|}
\hline Examination finding & Possible significance \\
\hline Poor growth & Renal disease \\
\hline Hypertension & Renal disease \\
\hline Wetness in the undergarments & Daytime incontinence \\
\hline Palpation of stool in abdomen & Constipation \\
\hline Perianal excoriation or vulvovaginitis & Pinworms \\
\hline $\begin{array}{l}\text { Abnormalities of lumbosacral spine } \\
\text { (midline hair tuft, abnormal gluteal fold) }\end{array}$ & Spinal dysraphism \\
\hline $\begin{array}{l}\text { Incomplete bladder emptying } \\
\text { (by percussion or palpation) }\end{array}$ & Urologic abnormality \\
\hline $\begin{array}{l}\text { Observation of slow urinary stream, straining, } \\
\text { dribbling, intermittent stream }\end{array}$ & Urologic abnormality \\
\hline $\begin{array}{l}\text { Abnormal neurologic examination of the } \\
\text { perineum and lower extremities }\end{array}$ & Spinal cord abnormality \\
\hline
\end{tabular}

$\mathrm{NE}$ and correlates positive aspects of the history with their clinical significance.

\section{Investigations}

If the child's history is not clearly primary monosymptomatic $\mathrm{NE}$, it is reasonable and recommended to have the child undergo further investigation [Figure 2]. ${ }^{[53]} \mathrm{A}$ urine analysis (UA) can be obtained as a screening tool for possible medical conditions such as: Infection, diabetes mellitus or insipidus. ${ }^{[51]}$ If the results of the UA indicate possible infection, urine culture is then indicated. If the history and physical exam have raised the suspicion of urinary obstruction, structural abnormalities, recurrent infection or significant daytime symptoms, a postvoid residual volume (PVR) and bladder/renal ultrasound should be obtained. ${ }^{[51]}$ According to the ICCS guidelines, a normal PVR in a child, whom you expect to have the capability of emptying their bladder completely, is age dependent. Children 4-6 years old, with a single PVR $30 \mathrm{~mL}$ or $>21 \%$ of estimated BC or repeated PVR $>20 \mathrm{~mL}$ or $>10 \%$ of $\mathrm{BC}$ is abnormal, and children $7-12$ years old with a single PVR $20 \mathrm{~mL}$ or $>15 \%$ BC or PVR $>10 \mathrm{~mL}$ or $>6 \%$ of $\mathrm{BC}$ is abnormal. ${ }^{[1]}$ Initial imaging of the urinary anatomy with renal and bladder US is indicated, if there is a high suspicion of an anatomic anomaly, spina bifida occulta or neurogenic bladder. ${ }^{[54]}$ Further imaging with magnetic resonance imaging and/or urodynamic studies may become indicated [Figure 2]. ${ }^{[54]}$ Other more invasive investigations, such as: Voiding cystourethrogram, retrograde urethrogram and urodynamic testing, while outside the scope of this review, are indicated in certain instances, like spinal cord anomalies or frequent urinary tract infections.

Almost all children seen at our institution for NE are referred to us by their primary care physician having failed initial treatment. No further investigation is usually required before we feel comfortable enough to begin both a diagnostic and therapeutic treatment trial.

\section{TREATMENT}

We will focus on the treatment strategies for primary monosymptomatic NE, as the treatment for secondary $\mathrm{NE}$, involves treating the underlying stressor or medical condition causing the regression, and if no cause can be identified, these patients are treated in the same fashion as children with primary NE. ${ }^{[48,51]}$

\section{Behavioral}

In our experience, first line treatment for both our patients and their families is education. NE can be a frustrating and 


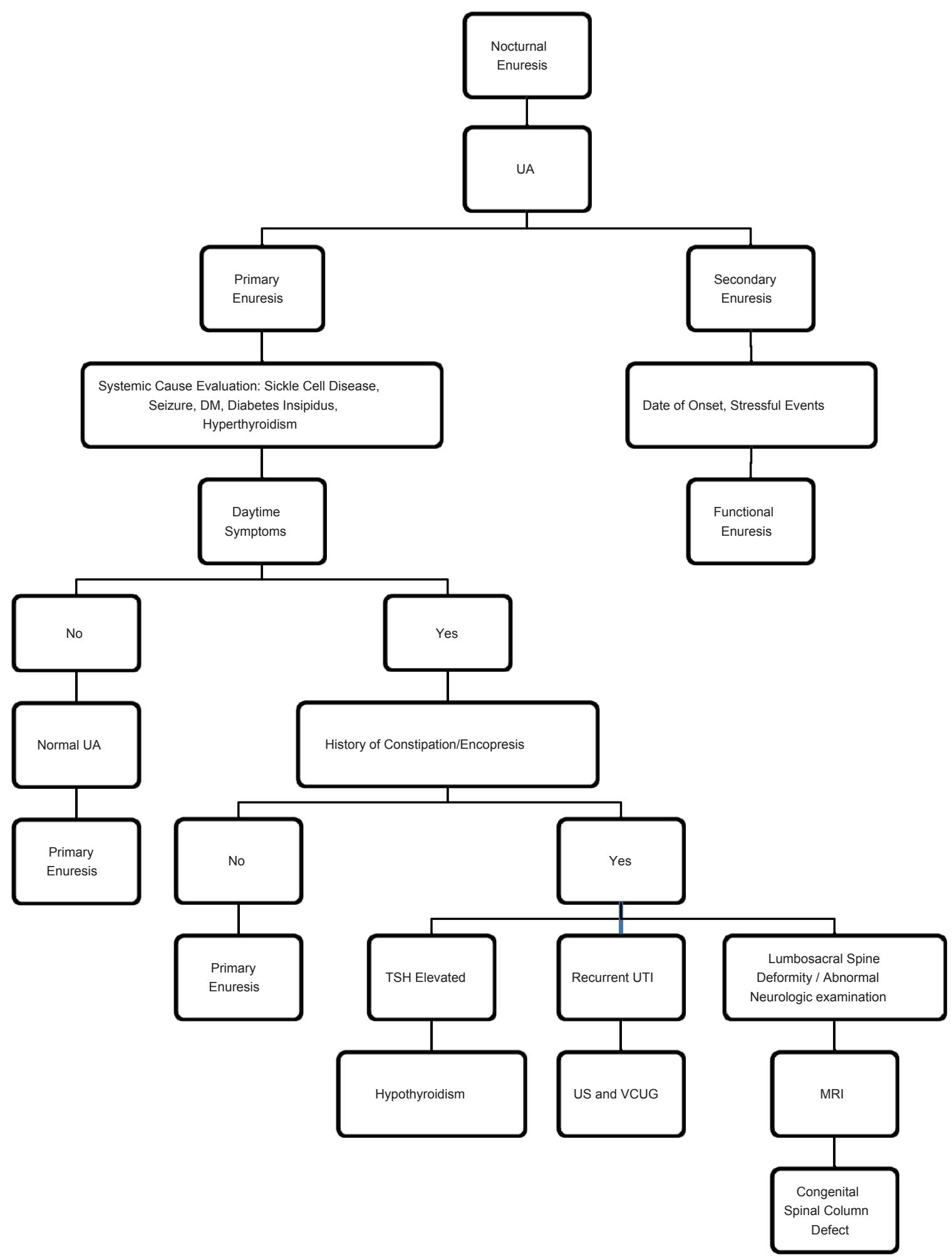

Figure 2: Nocturnal enuresis algorithm (adapted from Gomelia LG. Nocutrnal Enuresis Algorithm. The 5-Min Clinical Consult 2013. Lippincott Williams and Wilkins, May 18, 2012)

embarrassing condition for patients and their families alike. ${ }^{[55,56]}$ Taking extra time to educate, reassure, and fully answer questions of the children and their caretakers about NE is of the utmost importance. As previously stated, the majority of children with NE will have spontaneous resolution, such that education and reassurance involves not only prognosis, but also the setting of goals. The ICCS guidelines define response to treatment in terms of initial success and long-term success [Table 4], which can be helpful in define treatment goals. ${ }^{[1]}$ In general, the goal of NE treatment will include: 
Reducing the total number of enuretic nights, avoiding enuresis on specific nights in specific locations, stress reduction for the child and family and the avoidance of NE recurrence. ${ }^{[4,57,58]}$

The next step in the treatment for NE is behavioral therapy, also known as urotherapy. Urotherapy is a nonpharmacologic and nonsurgical treatment for NE which includes education on: Normal bladder function, normal voiding habits, how the child differs from normal, and how to change voiding behavior (posture, timing, holding maneuvers). This is especially beneficial in nonmonosymptomatic NE to normalize the function of the bladder during the daytime, which will improve the function at night as well. Urotherapy involves advice regarding fluid intake and the avoidance of constipation, support for the family and caregivers when needed, and regular follow-up appointments. ${ }^{[1]}$

We instruct our patients to begin timed voiding once every 3-4 h. We also advise our patients to stay hydrated, but to shift fluid intake habits by drinking $2 / 3^{\text {rd }}$ of their normal total daily fluids during the morning to early afternoon and then other $1 / 3^{\text {rd }}$ the remainder of the day. We also advise a decrease in the amount of diuretic fluids the child may drink, that is, coffee, tea or soda. It is also important to us that the child stops all fluid intake 1-2 $\mathrm{h}$ before bedtime, and empty his or her bladder immediately before bedtime. At our institution, if the patients and their families have not already done so, they are advised to keep both a bladder and bowel diary during the time between their next visit.

Motivational therapy (positive reinforcement), prizes or stickers for following the urotherapy guidelines and for periods of extended dryness, is helpful for children who are motivated to treat their NE. ${ }^{[59]}$ In children between 5yo and 7 yo with mild symptoms (enuresis $<7$ nights/week), this type of intervention has been shown to be $25 \%$ effective with a relapse rate of approximately $5 \%$ and reported symptom improvement in $80 \%$ of patients. ${ }^{[48,59-65]}$

It should be stressed that punishment (negative reinforcement) is NOT an acceptable treatment option. Punishment is not only ineffective, it can counterproductive by enhancing stress related accidents and at its worst, abusive. ${ }^{[51,55,56,59,66,67]}$

\begin{tabular}{|c|c|c|}
\hline $\begin{array}{l}\text { Success } \\
\text { type }\end{array}$ & Term & Definition \\
\hline Initial & $\begin{array}{l}\text { Nonresponse } \\
\text { Partial response } \\
\text { Full response }\end{array}$ & $\begin{array}{l}0 \%-49 \% \text { decrease in symptom frequency } \\
50 \%-99 \% \text { decrease in symptom frequency } \\
100 \% \text { decrease in symptom frequency }\end{array}$ \\
\hline Long-term & $\begin{array}{l}\text { Relapse } \\
\text { Continued success } \\
\text { Complete success }\end{array}$ & $\begin{array}{l}>1 \text { symptom recurrence in I month } \\
\geq 6 \text { months without relapse off of } \\
\text { treatment } \\
\geq 2 \text { years without relapse off of treatment }\end{array}$ \\
\hline
\end{tabular}

\section{Alarms}

In general, clinicians allow 6 weeks to evaluate the effectiveness of behavioral and motivational therapy before implementing more invasive treatment strategies. If behavioral therapy is ineffective after 6 weeks, the addition of enuresis alarms is appropriate. ${ }^{[51,68,69]}$ Enuresis alarms are electronic devices that are worn or placed in bed that will provide a signal, most commonly loud acoustic noise, when it senses an episode of incontinence. ${ }^{[1]}$ Meta analyses have shown enuresis alarms up to $66 \%$ effective, noninferior to Desmopressin and more effective than tricyclic antidepressants (TCAs) in children who are motivated and have the cognitive capacity to understand the alarm system. ${ }^{[68,70,71]}$ However, several studies have demonstrated compliance difficulties with these devices, for various practical reasons including cost, difficulties in set up, and discontinuing the use due to: Failure of the alarm to wake the child, false alarms, alarm failure and skin irritation. ${ }^{[58,72,73]}$

At our institution, patients are typically referred after pediatricians and primary care physicians have begun preliminary treatments. Generally, patients have already tried behavioral therapy, urotherapy therapy and in many cases either failed or declined alarm device for several reasons. We also observed a cultural bias against alarm devices in many cases. In addition to the above difficulties, we encounter concerned families regarding multiple sleep interruptions possibly being detrimental to the child. Based on those practical difficulties and possible side-effects based on our observation and experiences from families regarding discussion about alarm device treatment, we have created our own treatment algorithm to fit our population [Figure 3]. However, with the advent of and wide availability of "smart" phones, the use of applications may aid and ease the use of alarms, and may be an area of research in the future. ${ }^{[1]}$

\section{Medications}

Desmopressin (DDAVP) is a synthetic $\mathrm{ADH}$, and in tablet or nasal form, is indicated for children $>5$ years old with NE refractory to urotherapy. ${ }^{[74]}$ In addition to alarm therapy, desmopressin therapy is recommended as first line treatment for patients with primary monosymptomatic NE with an International Consultation on Incontinence (ICS) level 1 grade A recommendation. ${ }^{[75,76]}$ DDAVP is generally considered to be a relatively benign medication, especially at low doses, ${ }^{[76]}$ however, a base line CMP may be advised because DDAVP is contraindicated in children with a history of hyponatremia. ${ }^{[77]}$ According to the literature, DDAVP monotherapy has been shown to achieve total success in as much as $30 \%$ of children, with an additional $40 \%$ experiencing significant improvement. ${ }^{[51,69]}$ However, studies comparing its effectiveness to enuresis alarms have demonstrated a 


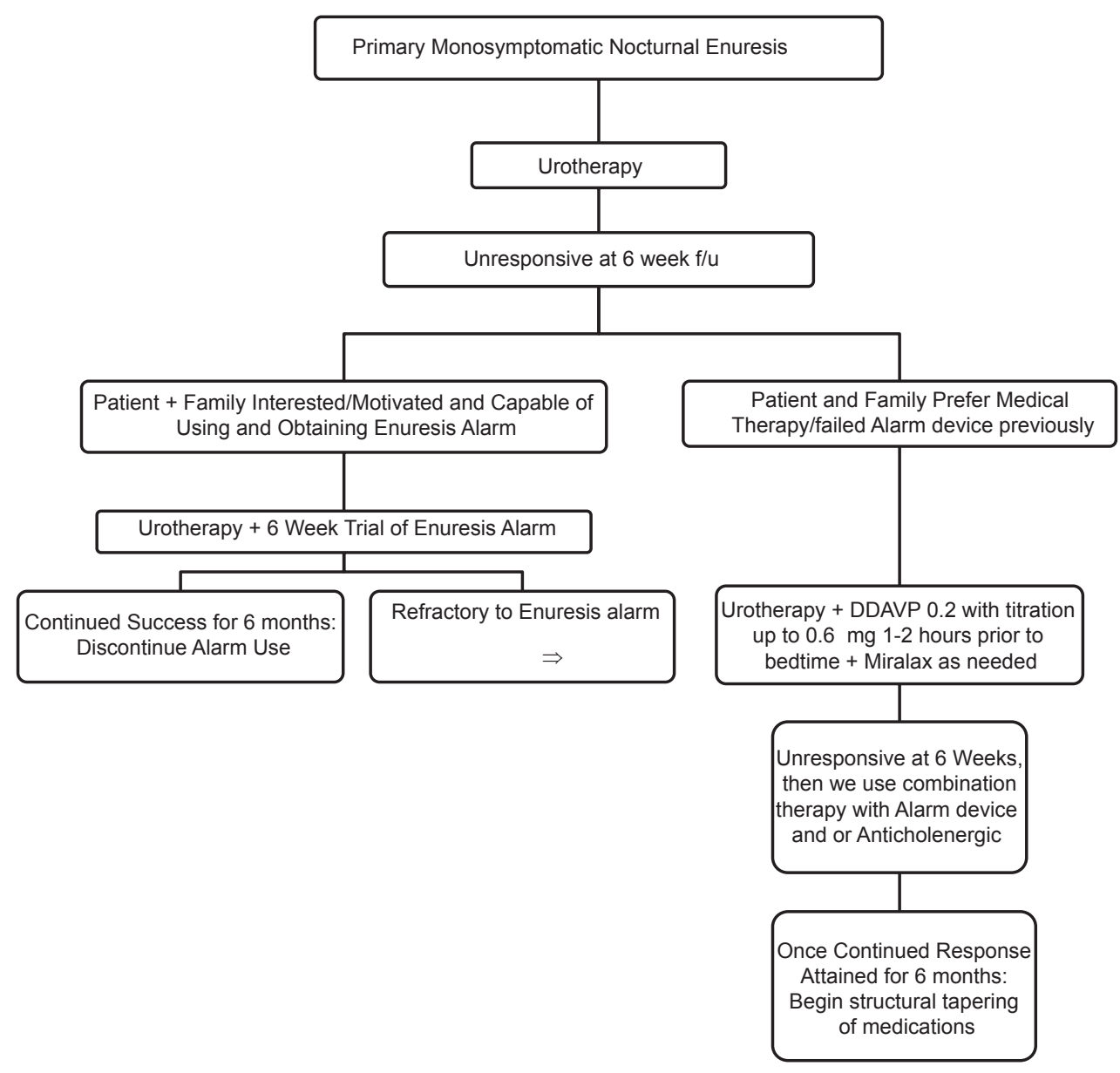

Figure 3: Primary nocturnal enuresis treatment algorithm

recurrence rate of up to $70 \%$ following discontinuation..$^{[71]}$ Conversely, more recent studies have shown Desmopressin treatment with a structured medication withdrawal protocol may have superior response rate than those from alarm therapy alone. ${ }^{[76,78]}$ We have observed similar results, thus we recommend tapering off the dose of DDAVP, as the risk of recurrence has decreased in our experience.

After initial failure or recurrence after monotherapy with either DDAVP or alarm device, combination therapy of DDAVP and alarm device has shown to be helpful in children with severe symptoms, behavioral and familiar difficulties. ${ }^{[79]}$ However, other studies have demonstrated that DDAVP does not enhance alarm response. ${ }^{[80]}$ This is an area of continued discussion and hopefully the subject of future research. ${ }^{[51]}$

Anticholinergic medications, such as oxybutynin (Ditropan) have been used to treat urinary urgency, frequency and incontinence. ${ }^{[81]}$ Anticholenergic medications act by relaxing the smooth muscles of bladder increasing BC. ${ }^{[81]}$ Little literature exists on anticholenergic monotherapy, as it is not considered first line therapy, ${ }^{[82,83]}$ however there are several studies examining combination therapy of DDAVP with anticholenergic medication. ${ }^{[84,85]}$ These studies have found this combination therapy is both safe and effective (57-66\%) in children refractory to initial therapies. ${ }^{[84,85]}$ In our practice, we have not seen benefit from anticholinergic medications alone in treating monosymptomatic NE. We do, however, use oxybutynin in combination with DDAVP in attempts to relax the bladder to provide more bladder capacitance, especially in patients with daytime LUT symptoms. This strategy has shown benefit in our experience, consistent with the literature. ${ }^{[34,35,84-86]}$ There is concern about anticholinergic side effects, specifically constipation. ${ }^{[81]}$ Similar to all of our patients, these patients, especially those constipated, are started on a stool softener (Miralax).

For children with NE refractory to behavioral therapy, DDAVP and anticholinergic therapy, imipramine, a TCA is indicated. ${ }^{[87]}$ It has demonstrated a $20 \%$ complete success rate in treating NE compared to the placebo response of $5 \%(P=0.05)$, however, a relapse rate of $96 \%$ when the medication was discontinued. ${ }^{[51,88,89]}$ Imipramine, as well as all other TCAs, have a black box warning of increased suicidality. ${ }^{[7]}$ It is for this reason, and others, such as, the risk of overdose, 
concomitant constipation, cardiotoxicity and its relatively limited efficacy, that we do not recommend Imipramine therapy to our patients, unless absolutely necessary. ${ }^{[87]}$

As previously stated, both urinary and bowel dysfunction are associated. ${ }^{[0]}$ Encopresis is discussed extensively in the literature, in our population we observed a large percentage of children suffering from NE to have comorbid constipation. Miralax (Polyethelyne Glycol 3350 OTC), a balanced polyethylene glycol, is a nonabsorbable osmotic laxative that has been shown not to cause significant fluid or electrolyte shifts; it is therefore safe to be used for patients in all age groups. ${ }^{[90,91]}$

\section{CONCLUSION}

The treatment of NE remains a challenge for many pediatricians and pediatric urologists. This likely stems from the multiple possible etiologies of the disorder. We have established a treatment algorithm at our institution, which we have found successful in the majority of our patients [Figure 3]. This consists of starting patients on urotherapy, decreasing diuretic fluids intake, stopping fluid intake 1-2 h before bedtime, and emptying their bladder right before bedtime. Most patients presenting to our institution have already been advised to make these changes and have either seen no response or have been unable or unmotivated to adhere to all of the recommendations. We then educate our patients and their parents about other treatment options including enuresis alarms or medication. Most of our patients and their parents opt for medication for different reasons. We advise continuing urotherapy and at the same time we start DDAVP $0.2 \mathrm{mg}$ 1-2 $\mathrm{h}$ prior to bedtime, titrating the dose once every 1 week up to $0.6 \mathrm{mg}$ based on clinical response. We start patients on a Miralax, as constipation is commonly a contributing factor. If the NE continues we discuss combination therapy with alarm device or weight based anti-cholingerics to the regimen. All medications are weaned off in the same manner they were started to help decreased the rate of recurrence. Finally, our hope is in the future with further research we will continue to improve the treatment NE.

\section{REFERENCES}

1. Austin PF, Bauer SB, Bower W, Chase J, Franco I, Hoebeke P, et al. The Standardization of Terminology of Lower Urinary Tract Function in Children and Adolescents: Update Report from the Standardization Committee of the International Children's Continence Society.J Urol 2014.

2. Nevéus T, von Gontard A, Hoebeke P, Hjälmås K, Bauer S, Bower W, et $a l$. The standardization of terminology of lower urinary tract function in children and adolescents: Report from the Standardisation Committee of the International Children's Continence Society. J Urol 2006;176:314-24.

3. von Gontard A, Mauer-Mucke K, Plück J, Berner W, Lehmkuhl G. Clinical behavioral problems in day-and night-wetting children. Pediatr Nephrol 1999;13:662-7.
4. Robson WL, Leung AK. Secondary nocturnal enuresis. Clin Pediatr (Phila) 2000;39:379-85.

5. Ropper AH, Samuels MA. Sleep and Its Abnormalities. Adams and Victor's Principles of Neurology. 9th ed., Ch. 19. New York: McGraw-Hill; 2009. Available from: http://www.accessmedicine.mhmedical.com/ content.aspx ?bookid $=354$ and Sectionid $=40236327$. [Last accessed on 2014 April 08].

6. Bakker E, van Sprundel M, van der Auwera JC, van Gool JD, Wyndaele JJ. Voiding habits and wetting in a population of 4,332 Belgian schoolchildren aged between 10 and 14 years. Scand J Urol Nephrol 2002;36:354-62.

7. Klackenberg G. Nocturnal enuresis in a longitudinal perspective. A primary problem of maturity and/or a secondary environmental reaction? Acta Paediatr Scand 1981;70:453-7.

8. Taras HL. Children. In: Feldman MD, Christensen JF, editors. Behavioral Medicine: A Guide for Clinical Practice. 3rd ed., Ch. 9. New York: McGraw-Hill; 2008. Available from: http://www.accessmedicine. mhmedical.com/content.aspx?bookid $=373 \&$ Sectionid $=39732006$. [Last accessed on 2014 Apr 08].

9. Fergusson DM, Horwood LJ, Shannon FT. Factors related to the age of attainment of nocturnal bladder control: An 8-year longitudinal study. Pediatrics 1986;78:884-90.

10. Howe AC, Walker CE. Behavioral management of toilet training, enuresis, and encopresis. Pediatr Clin North Am 1992;39:413-32.

11. Forsythe WI, Redmond A. Enuresis and spontaneous cure rate. Study of 1129 enuretis. Arch Dis Child 1974;49:259-63.

12. Koff S. Enuresis. In: Walsh P, Retik A Jr, editors. Campbell's Urology. $7^{\text {th }}$ ed. Philadelphia: WB Saunders; 1998. p. 2055.

13. Rushton HG. Wetting and functional voiding disorders. Urol Clin North Am 1995;22:75-93.

14. Joinson C, Heron J, Butler R, Von Gontard A, Butler U, Emond A, et al. A United Kingdom population-based study of intellectual capacities in children with and without soiling, daytime wetting, and bed-wetting. Pediatrics 2007;120:e308-16.

15. Hägglöf B, Andrén O, Bergström E, Marklund L, Wendelius M. Selfesteem before and after treatment in children with nocturnal enuresis and urinary incontinence. Scand J Urol Nephrol Suppl 1997;183:79-82.

16. Baeyens D, Roeyers H, Hoebeke P, Verté S, Van Hoecke E, Walle JV. Attention deficit/hyperactivity disorder in children with nocturnal enuresis. J Urol 2004;171:2576-9.

17. Mellon MW, Natchev BE, Katusic SK, Colligan RC, Weaver AL, Voigt RG, et al. Incidence of enuresis and encopresis among children with attention-deficit/hyperactivity disorder in a population-based birth cohort. Acad Pediatr 2013;13:322-7.

18. Nevéus T. Diagnosis and management of nocturnal enuresis. Curr Opin Pediatr 2009;21:199-202.

19. Robson WL. Clinical practice. Evaluation and management of enuresis. N Engl J Med 2009;360:1429-36.

20. Aikawa T, Kasahara T, Uchiyama M. The arginine-vasopressin secretion profile of children with primary nocturnal enuresis. Eur Urol 1998;33 Suppl 3:41-4.

21. Rittig S, Knudsen UB, Nørgaard JP, Gregersen H, Pedersen EB, Djurhuus JC. Diurnal variation of plasma atrial natriuretic peptide in normals and patients with enuresis nocturna. Scand J Clin Lab Invest 1991;51:209-17.

22. Pomeranz A, Abu-Kheat G, Korzets Z, Wolach B. Night-time polyuria and urine hypo-osmolality in enuretics identified by nocturnal sequential urine sampling - Do they represent a subset of relative ADH-deficient subjects? Scand J Urol Nephrol 2000;34:199-202.

23. Aceto G, Penza R, Delvecchio M, Chiozza ML, Cimador M, Caione P. Sodium fraction excretion rate in nocturnal enuresis correlates with nocturnal polyuria and osmolality. J Urol 2004;171:2567-70.

24. Rittig S, Schaumburg HL, Siggaard C, Schmidt F, Djurhuus JC. The circadian defect in plasma vasopressin and urine output is related to 
desmopressin response and enuresis status in children with nocturnal enuresis. J Urol 2008;179:2389-95.

25. Kawauchi A, Watanabe H, Nakagawa S, Miyoshi K. Development of bladder capacity, nocturnal urinary volume and urinary behavior in nonenuretic and enuretic children. Nihon Hinyokika Gakkai Zasshi 1993;84:1811-20.

26. Yeung CK, Sit FK, To LK, Chiu HN, Sihoe JD, Lee E, et al. Reduction in nocturnal functional bladder capacity is a common factor in the pathogenesis of refractory nocturnal enuresis. BJU Int 2002;90:302-7.

27. George CP, Messerli FH, Genest J, Nowaczynski W, Boucher R, Kuchel Orofo-Oftega M. Diurnal variation of plasma vasopressin in man. J Clin Endocrinol Metab 1975;41:332-8.

28. Rittig S, Matthiesen TB, Pedersen EB, Djurhuus JC. Circadian variation of angiotensin II and aldosterone in nocturnal enuresis: Relationship to arterial blood pressure and urine output. J Urol 2006;176:774-80.

29. Koff SA. Estimating bladder capacity in children. Urology 1983;21:248.

30. Troup CW, Hodgson NB. Nocturnal functional bladder capacity in enuretic children. Wis Med J 1971;70:171-3.

31. Kawauchi A, Tanaka Y, Naito Y, Yamao Y, Ukimura O, Yoneda K, et al. Bladder capacity at the time of enuresis. Urology 2003;61:1016-8.

32. Watanabe H, Azuma Y. A proposal for a classification system of enuresis based on overnight simultaneous monitoring of electroencephalography and cystometry. Sleep 1989;12:257-64.

33. Van Hoeck K, Bael A, Lax H, Hirche H, Van Dessel E, Van Renthergem $\mathrm{D}$, et al. Urine output rate and maximum volume voided in school-age children with and without nocturnal enuresis. J Pediatr 2007;151:575-80.

34. Nevéus T, Läckgren G, Tuvemo T, Olsson U, Stenberg A. Desmopressin resistant enuresis: Pathogenetic and therapeutic considerations. J Urol 1999;162:2136-40.

35. Radvanska E, Kovács L, Rittig S. The role of bladder capacity in antidiuretic and anticholinergic treatment for nocturnal enuresis. J Urol 2006;176:764-8.

36. Wolfish N. Sleep arousal function in enuretic males. Scand J Urol Nephrol Suppl 1999;202:24-6.

37. Hunsballe JM. Increased delta component in computerized sleep electroencephalographic analysis suggests abnormally deep sleep in primary monosymptomatic nocturnal enuresis. Scand J Urol Nephrol 2000;34:294-302.

38. Yeung CK, Diao M, Sreedhar B. Cortical arousal in children with severe enuresis. N Engl J Med 2008;358:2414-5.

39. Bader G, Nevéus T, Kruse S, Sillén U. Sleep of primary enuretic children and controls. Sleep 2002;25:579-83.

40. Ornitz EM, Russell AT, Hanna GL, Gabikian P, Gehricke JG, Song D, et al. Prepulse inhibition of startle and the neurobiology of primary nocturnal enuresis. Biol Psychiatry 1999;45:1455-66.

41. Bower WF, Diao M, Tang JL, Yeung CK. Acupuncture for nocturnal enuresis in children: A systematic review and exploration of rationale. Neurourol Urodyn 2005;24:267-72.

42. Iscan A, Ozkul Y, Unal D, Soran M, Kati M, Bozlar S, et al. Abnormalities in event-related potential and brainstem auditory evoked response in children with nocturnal enuresis. Brain Dev 2002;24:681-7.

43. Freitag CM, Röhling D, Seifen S, Pukrop R, von Gontard A. Neurophysiology of nocturnal enuresis: Evoked potentials and prepulse inhibition of the startle reflex. Dev Med Child Neurol 2006;48:278-84.

44. Bakwin H. The genetics of enuresis. In: Kolvin RM, Meadows SR editors. Bladder Control and Enuresis. London: Medical Books Ltd.; 1973. p. 73.

45. Bakwin H. Enuresis in twins. Am J Dis Child 1971;121:222-5.

46. Natarajan K, Townes TM, Kutlar A. Disorders of hemoglobin structure: Sickle cell anemia and related abnormalities. In: Lichtman MA, Kipps TJ, Seligsohn U, Kaushansky K, Prchal JT, editors. Williams Hematology. $8^{\text {th }}$ ed., Ch. 48. New York: McGraw-Hill; 2010. Available from: http:// www.accessmedicine.mhmedical.com/content.aspx?bookid $=358 \&$ Se ctionid $=39835866$. [Last accessed on 2014 Apr 08].
47. Bunik M, Treitz M, Fox D. Ambulatory \& office pediatrics. In: Hay WW Jr, Levin MJ, Deterding RR, Abzug MJ, Sondheimer JM, editors. Current Diagnosis \& Treatment: Pediatrics. $21^{\text {th }}$ ed., Ch. 9. New York: McGraw-Hill; 2012. Available from: http:/www.accessmedicine. mhmedical.com/content.aspx?bookid $=497 \&$ Sectionid $=40851676$. [Last accessed on $2014 \mathrm{Apr}$ 12].

48. Tu ND, Baskin LS, Arnhym AM. Eitiology and evaluation of nocturnal enuresis in children. In: Torchia MM, editor. Up To Date. Waltham, MA: Up To Date; 2014.

49. Ellsworth P, Caldamone A. Pediatric voiding dysfunction: Current evaluation and management. Urol Nurs 2008;28:249-57, 283.

50. Koh H, Lee MJ, Kim MJ, Shin JI, Chung KS. Simple diagnostic approach to childhood fecal retention using the Leech score and Bristol stool form scale in medical practice. J Gastroenterol Hepatol 2010;25:334-8.

51. Neveus T, Eggert P, Evans J, Macedo A, Rittig S, Tekguil S, et al. Evaluation of and treatment for monosymptomatic enuresis: A standardization document from the International Children's Continence Society. J Urol 2010;183:441-7.

52. Vande Walle J, Rittig S, Bauer S, Eggert P, Marschall-Kehrel D, Tekgul S, et al. Practical consensus guidelines for the management of enuresis. Eur J Pediatr 2012;171:971-83.

53. Gomelia LG. Nocutrnal Enuresis Algorithm. The 5-Minute Clinical Consult 2013. Philadelphia: Lippincott Williams and Wilkins; 2012.

54. Pippi Salle JL, Capolicchio G, Houle AM, Vernet O, Jednak R, O'Gorman AM, et al. Magnetic resonance imaging in children with voiding dysfunction: Is it indicated? J Urol 1998;160:1080-3.

55. Jalkut MW, Lerman SE, Churchill BM. Enuresis. Pediatr Clin North Am 2001;48:1461-88.

56. Shelov SP, Gundy J, Weiss JC, McIntire MS, Olness K, Staub HP, et al. Enuresis: A contrast of attitudes of parents and physicians. Pediatrics 1981;67:707-10.

57. Van Hoeck KJ, Bael A, Lax H, Hirche H, Bernaerts K, Vandermaelen V, et al. Improving the cure rate of alarm treatment for monosymptomatic nocturnal enuresis by increasing bladder capacity - A randomized controlled trial in children. J Urol 2008;179:1122-6.

58. Schmitt BD. Nocturnal enuresis. Pediatr Rev 1997;18:183-90.

59. National Institute for Health and Care Excellence. Nocturnal Enuresis-the Management of Bedwetting in Children and Young People. Available from: http://www.nice.org.uk/guidance/index. jsp?action $=$ download $\& 0=51367$. [Last accessed on 2014 Apr 09].

60. Baker BL. Symptom treatment and symptom substitution in enuresis. J Abnorm Psychol 1969;74:42-9.

61. Longstaffe S, Moffatt ME, Whalen JC. Behavioral and self-concept changes after six months of enuresis treatment: A randomized, controlled trial. Pediatrics 2000;105:935-40.

62. Caldwell PH, Nankivell G, Sureshkumar P. Simple behavioural interventions for nocturnal enuresis in children. Cochrane Database Syst Rev 2013;7:CD003637.

63. Marshall S, Marshall HH, Lyon RP. Enuresis: An analysis of various therapeutic approaches. Pediatrics 1973;52:813-7.

64. Schmitt BD. Nocturnal enuresis: An update on treatment. Pediatr Clin North Am 1982;29:21-36.

65. Rushton HG. Nocturnal enuresis: Epidemiology, evaluation, and currently available treatment options. J Pediatr 1989;114:691-6.

66. Pediatric Society New Zealand. Noctural Enuresis "Bedwetting," 2005. Available from: http://www.paediatrics.org.nz/files/guidelines/ Enuresisguidelinefinalendorsed.pdf. [Last accessed on 2014 Apr 10].

67. Schmitt BD. Seven deadly sins of childhood: Advising parents about difficult developmental phases. Child Abuse Negl 1987;11:421-32.

68. Glazener CM, Evans JH, Peto RE. Alarm interventions for nocturnal enuresis in children. Cochrane Database Syst Rev 2005:CD002911.

69. Glazener CM, Evans JH. Desmopressin for nocturnal enuresis in children. Cochrane Database Syst Rev 2002:CD002112.

70. Monda JM, Husmann DA. Primary nocturnal enuresis: A comparison 